INTERVENTIONAL CARDIOLOGY AND SURGERY

\title{
Comparison of outcomes after aortic valve replacement with a mechanical valve or a bioprosthesis using microsimulation
}

\author{
J P A Puvimanasinghe, J J M Takkenberg, M B Edwards, M J C Eijkemans, E W Steyerberg, \\ L A van Herwerden, K M Taylor, G L Grunkemeier, J D F Habbema, A J J C Bogers
}

Heart 2004;90:1172-1178. doi: 10.1136/hrt.2003.013102

See end of article for authors' affiliations

\section{Correspondence to:} Dr J P A Puvimanasinghe, Department of Cardiothoracic Surgery, Room Bd 162a, Erasmus MC Rotterdam,

Netherlands:

i.p.a.puvimanasinghe@ erasmusmc.nl

Accepted

12 December 2003

\begin{abstract}
Background: Mechanical valves and bioprostheses are widely used for aortic valve replacement. Though previous randomised studies indicate that there is no important difference in outcome after implantation with either type of valve, knowledge of outcomes after aortic valve replacement is incomplete.

Objective: To predict age and sex specific outcomes of patients after aortic valve replacement with bileaflet mechanical valves and stented porcine bioprostheses, and to provide evidence based support for the choice of prosthesis.

Methods: Meta-analysis of published results of primary aortic valve replacement with bileaflet mechanical prostheses (nine reports, 4274 patients, and 25726 patient-years) and stented porcine bioprostheses (13 reports, 9007 patients, and 54151 patient-years) was used to estimate the annual risks of postoperative valve related events and their outcomes. These estimates were entered into a microsimulation model, which was employed to calculate age and sex specific outcomes after aortic valve replacement.

Results: Life expectancy (LE) and event-free life expectancy (EFLE) for a 65 year old man after implantation with a mechanical valve or a bioprosthesis were 10.4 and 10.7 years and 7.7 and 8.4 years, respectively. The lifetime risk of at least one valve related event for a mechanical valve was $48 \%$, and for a bioprosthesis, $44 \%$. For LE and EFLE, the age crossover point between the two valve types was 59 and 60 years, respectively.

Conclusions: Meta-analysis based microsimulation provides insight into the long term outcome after aortic valve replacement and suggests that the currently recommended age threshold for implanting a bioprosthesis could be lowered further.
\end{abstract}

M echanical valves and bioprostheses are common valve types used in aortic valve replacement. ${ }^{12}$ However, both are known to have inherent advantages and disadvantages. Mechanical valves, for example, offer long term durability but are thrombogenic, necessitating life long anticoagulation that carries an increased risk of haemorrhage. In contrast, bioprostheses are less thrombogenic, which in most patients obviates the need for long term anticoagulant agents; however, their propensity to undergo structural valvar deterioration (SVD) limits their durability. ${ }^{3}$ The risk of haemorrhage with mechanical valves and the risk of SVD in bioprostheses are age dependent, the first increasing and the latter decreasing with advancing age. ${ }^{45}$ Consequently, the choice between a mechanical valve and a bioprosthesis for a given patient undergoing aortic valve replacement involves striking a balance between the risks and benefits of each valve type. Thus a knowledge of the outcomes after aortic valve replacement for each type of valve could assist surgeons in their choice of valve. Microsimulation and associated simulation techniques are capable of providing insight into outcomes after aortic valve replacement. We therefore combined meta-analyses of several clinical studies with microsimulation to study the outcomes of patients after aortic valve replacement with bileaflet mechanical valves and stented porcine bioprostheses.

\section{METHODS}

\section{Meta-analysis}

We conducted a literature search of the Medline database using the PubMed search interface to identify reports which considered the following valves: St Jude Medical (SJM) bileaflet valves, "standard" and "haemodynamic plus" models (St Jude Medical Inc, Minneapolis, Minnesota, USA); Carpentier-Edwards "standard" and "supra-annular" valves (Baxter Healthcare Corporation, Chicago, Illinois, USA) or Hancock "standard," "modified orifice," and "Hancock II" valves (Medtronic Inc, Minneapolis, Minnesota, USA). The MeSH terms in combination with the text words "St Jude" for the mechanical valves and "stented," "Hancock," "Carpentier-Edwards," or "modified orifice" for the bioprostheses, respectively, were used for the search. The search was limited to the period January 1990 to October 2001 and to the English language. The title and abstracts of the studies obtained were screened for those that examined outcomes following aortic valve replacement. References in these reports were cross checked for other relevant studies. This resulted in 76 published reports for mechanical valves and 68 for bioprostheses. The following criteria for each valve type were then stipulated in order to obtain homogeneous groups of studies:

- Valves 19-33 mm in size, not focusing on a particular size or range.

- Patients >15 years of age; mean age of the study populations, $\geqslant 50$ years.

- Predominantly first time aortic valve replacement (>90\%).

- Aortic valve replacement with or without concomitant coronary artery bypass grafting (CABG) or any other valve repair procedure, but excluding other valve replacements.

Abbreviations: EFLE, event-free life expectancy; SVD, structural valvar deterioration; UKHVR, United Kingdom Heart Valve Registry 
- Valve related events ascertained according to standard definitions published in $1988^{6}$ and $1996{ }^{7}$

- For mechanical valves: an international normalised ratio (INR) between 1.8 and 4.5 .

Studies that had overlapping patient populations were excluded. Finally, nine reports on St Jude Medical mechanical valves ${ }^{4-15}$ and 13 reports on stented porcine bioprostheses $^{816-27}$ were selected. Heterogeneity in the selected publications was investigated by sensitivity analysis. Morbidity and mortality data on valve related events were obtained from these selected reports (see the appendix).

\section{Microsimulation}

The data on valve related events obtained from the metaanalysis were entered into a microsimulation model. This is a computer application that simulates the remaining lifetime of a given patient, taking into account all morbidity and mortality events and sequences of events that the patient might experience after aortic valve replacement. The basic structure of the model is shown in fig 1 .

The microsimulation model assumes that after aortic valve replacement a patient follows a course over time that can be adequately characterised by various discrete states. After aortic valve replacement, the patient can either die as a result of the operation, or can remain alive. The mortality of a patient who remains alive after aortic valve replacement is greater than that of a matched individual in the general population. This extra or excess mortality in the patient compared with a matched person in the general population reflects valve related events and "additional mortality" associated with the underlying valve pathology, left ventricular function, and the valve replacement procedure per se. ${ }^{28}$

The model incorporates the mortality experience of the general population, called the background mortality, by means of life tables of the relevant population (for example, American men). Mortality from valve related events is incorporated using the data obtained from the meta-analysis. The "additional mortality" experienced by patients having aortic valve replacement is not clearly defined or estimated at present. Thus we estimated age and sex specific hazard ratios to represent the effect of the "additional mortality". This was done by approximating age and sex specific survival curves produced by the model-which contained the background mortality and the mortality from valve related events-to the corresponding empirical curves obtained from published reports,$^{20}$ which contained all three components of mortality. Hazard ratios of 2.9, 1.8, 1.2, and 0.8 were estimated for male patients aged $45,55,65$, and 75 years, respectively.

The model calculates patient outcomes by superimposing the morbidity and mortality estimates of valve related events on the background mortality and additional mortality incorporated in the model. Ten thousand simulations of a given patient create a "virtual" patient population-that is, a cohort of patients with identical characteristics but with all possible outcomes after aortic valve replacement. From this large cohort of identical patients, the model calculates the average life expectancies and lifetime risks of valve related events for that given patient. A detailed account of the microsimulation structure and methodology has been supplied previously. ${ }^{29}$

\section{Validation}

To assess the agreement between age and sex specific model calculations and the corresponding true life experience of patients with aortic valve replacements, the results of the model were compared with the long term outcomes of patients in large datasets from Portland, Oregon, USA ${ }^{30}$ and the United Kingdom Heart Valve Registry (UKHVR), UK. ${ }^{31}$ The Portland dataset, from St Vincent Heart Institute, Portland, Oregon, contains 30 years of follow up data on patients who underwent aortic valve replacement with the Starr-Edwards mechanical prosthesis and the CarpentierEdwards "standard" bioprosthesis, and includes data on age, sex, and CABG. The UKHVR, which is based at the Hammersmith Hospital, London, is a computerised database that prospectively collects data on heart valve replacement surgery carried out in all cardiac centres throughout the UK. These include certain preoperative, implant, and postoperative data matched against individual patient demographics. All patients are followed up through the national agencies responsible for registering all deaths of UK nationals. The 15 year follow up data on bileaflet mechanical valves and stented porcine bioprostheses were used for the validation.

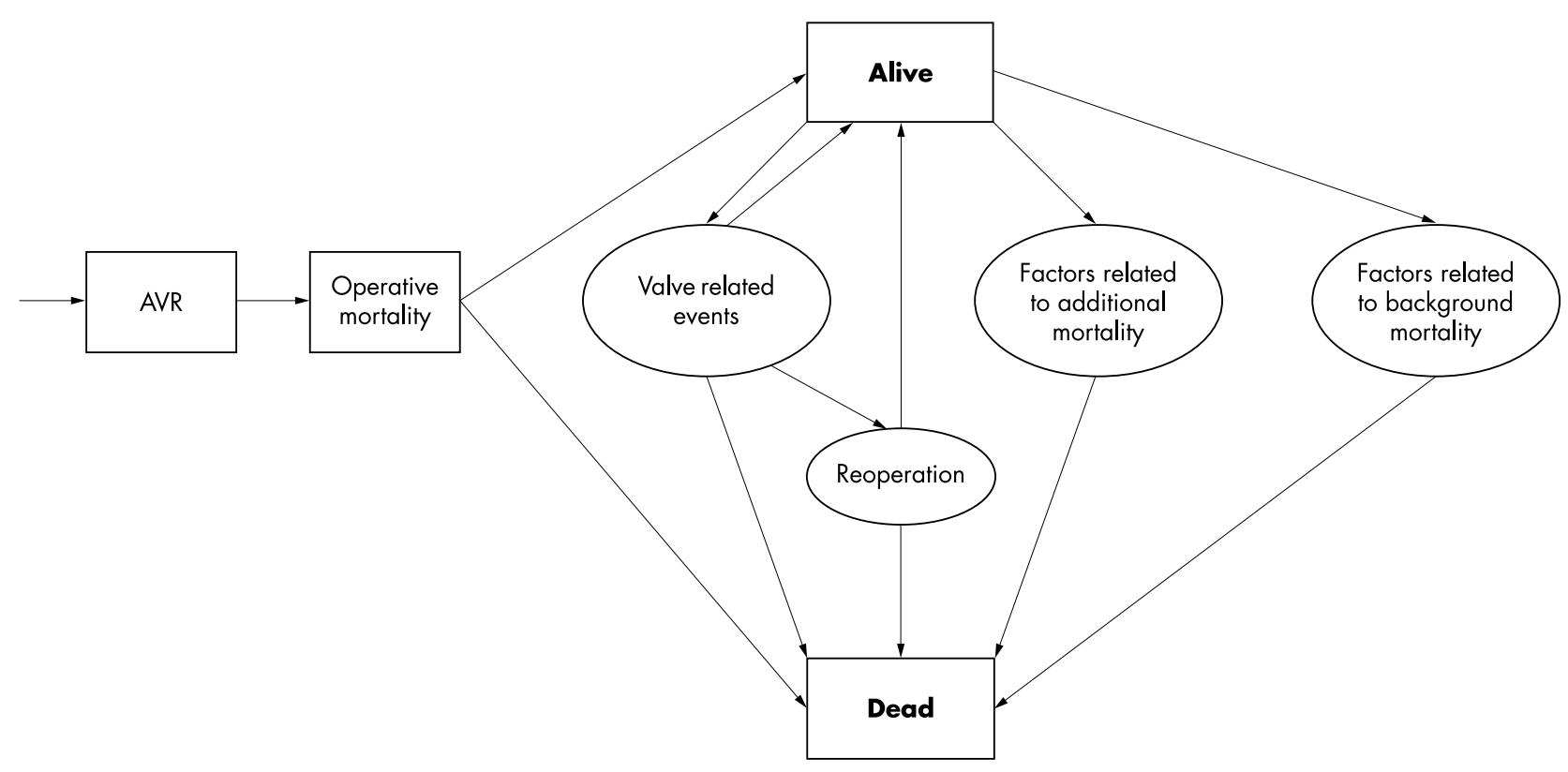

Figure 1 Basic structure of the microsimulation model. 
Table 1 Characteristics of the nine reports selected for the meta-analysis of St Jude Medical aortic valve prostheses

\begin{tabular}{|c|c|c|c|c|c|c|c|c|c|c|}
\hline & \multicolumn{9}{|c|}{ Reference No } & \multirow[b]{2}{*}{ Total } \\
\hline & 8 & 9 & 10 & 11 & 4 & 12 & 13 & 14 & 15 & \\
\hline Type of study & RS & RS & RS & PS & RS & PS & RS & RS & RS & \\
\hline Patients (n) & 412 & 351 & 694 & 418 & 666 & 204 & 178 & 773 & 578 & 4274 \\
\hline$\%$ Male & 59 & $72^{*}$ & 62 & 70 & 60 & $46^{*}$ & 63 & 69 & $\sim$ & 64 \\
\hline $\begin{array}{l}\text { Mean age } \\
\text { (years) }\end{array}$ & 62 & 54 & 58 & 55 & 66 & $52^{*}$ & 51 & 57 & $59^{*}$ & 59 \\
\hline $\begin{array}{l}\text { Follow up } \\
\text { (patient-years) }\end{array}$ & $1800^{*}$ & 1640 & 4502 & 2376 & 3881 & 1969 & 699 & 6419 & 2441 & 25726 \\
\hline $\begin{array}{l}\% \text { Concomitant } \\
\text { CABG }\end{array}$ & 42 & 22 & 24 & 27 & 50 & $\sim$ & 7 & 9* & 17 & 30 \\
\hline \multicolumn{11}{|c|}{$\begin{array}{l}\text { *Approximate figures. } \\
\text { D Data not available. } \\
\text { CABG, coronary artery bypass graft; PS, prospective study; RS, retrospective study. }\end{array}$} \\
\hline
\end{tabular}

\section{Sensitivity analysis}

A one way sensitivity analysis was conducted to investigate the effect of uncertainty in parameter estimates. Variation in the estimates of the valve related events by their 95\% confidence intervals resulted in very small variations in the life expectancies. Hence we defined larger ranges by increasing and decreasing the baseline estimates by $25 \%$. For SVD, the median time to SVD was varied by $10 \%$.

\section{RESULTS}

\section{Meta-analysis}

The nine selected reports on St Jude Medical mechanical valves comprised 4274 patients and a total follow up of 25726 patient-years. The 13 reports on stented porcine bioprostheses included 9007 valve recipients and 54151 patient-years of follow up. The mean age was 59.1 and 65.4 years, respectively. Approximately $65 \%$ of patients in both groups were male (tables 1 and 2). The incidence of valve related events and their outcomes are given in table 3 . The most frequent events were thromboembolism and haemorrhage in the mechanical valves, and thromboembolism and SVD in the bioprostheses. The incidence of endocarditis was $3.9 \%$ and $3.2 \%$ during the initial six months after implantation of mechanical and bioprostheses, respectively.

\section{Microsimulation}

The microsimulation model calculates total life expectancy and event-free life expectancy (EFLE) following aortic valve replacement with mechanical valves and bioprostheses for patients of either sex and of different ages. We give the results for male patients. For a 65 year old man, for example, life expectancy was 10.4 and 10.7 years and EFLE was 7.7 and 8.4 years, respectively, after implantation with a mechanical valve and a bioprosthesis. Comparisons of life expectancy and EFLE are shown in fig 2. When considering life expectancy and EFLE, the age crossover points between the two valve types were 59 and 60 years, respectively.

The lifetime risks of the more common valve related events are depicted in fig 3. As seen in fig 3A, the lifetime risk of SVD following a bioprosthesis reduces with advancing age at implantation, and is about $10 \%$ for a 75 year old patient. For the mechanical valves, the decreasing risk of thromboembolism with advancing age at implantation, concomitant on a decreasing life expectancy, is opposed by an increasing risk of haemorrhage (fig 3B). When considering the lifetime risk of experiencing at least one valve related event, the age crossover point for aortic valve replacement was 63 years.

\section{Validation}

The results from our model for male patients of different ages and for both valve types were compared with the corresponding long term survival data from Portland, Oregon. ${ }^{30}$ The overall agreement was favourable (fig 4, panels $\mathrm{A}$ and $\mathrm{B}$ ). Applying the UK background mortality estimates, we also compared model outputs with the 15 year experience of the UKHVR. ${ }^{31}$ Interestingly, the UK patients appeared to have a better survival. For example, when the model output for a 62 year old man who received a bioprosthesis was compared with a similar group of 60-65 year old men in the UKHVR, the 15 year survival calculated by the model was $36 \%$, as compared with $47 \%$ (40-53\%) in the UKHVR.

\section{Sensitivity analysis}

The EFLE for a 60 year old man and the corresponding age crossover point between the two valve types, for extreme values of some selected valve related events, are given in table 4. A change in the risk of SVD was shown to have the largest influence on EFLE and the age crossover point.

Table 2 Characteristics of the 13 reports selected for the meta-analysis of the stented porcine bioprostheses

\begin{tabular}{|c|c|c|c|c|c|c|c|c|c|c|c|c|c|c|}
\hline & \multicolumn{13}{|c|}{ Reference No } & \multirow[b]{2}{*}{ Total } \\
\hline & 16 & 17 & 18 & 19 & 20 & 21 & 22 & 23 & 8 & 24 & 25 & 26 & 27 & \\
\hline Type of study & PS & $\sim$ & PS & RS & RS & PS & RS & RS & RS & RS & RS & RS & $\sim$ & \\
\hline Patients (n) & 843 & 395 & 1108 & 165 & 1594 & 670 & 136 & 281 & 429 & 573 & 1823 & 561 & 429 & 9007 \\
\hline$\%$ Male & 58 & 62 & 49 & 70 & 71 & 75 & 85 & 62 & 72 & $\sim$ & $\sim$ & 70 & 73 & \\
\hline Mean age (years) & 69 & 66 & 74 & 67 & 60 & 65 & 50 & 75 & 64 & 59 & 69 & 72 & 64 & \\
\hline Follow up (patient-years) & 5093 & 1264 & 4735 & 551 & 10212 & 4813 & 1496 & 937 & 3000 & 5187 & 12640 & 1792 & 2431 & 54151 \\
\hline$\%$ Concomitant CABG & 43 & 31 & $\sim$ & 19 & 34 & 43 & 7 & $\sim$ & 35 & $\sim$ & 42 & 39 & 34 & 37 \\
\hline
\end{tabular}


Table 3 Pooled incidence of valve related events and their outcomes after aortic valve replacement with a mechanical valve and a bioprosthesis

\begin{tabular}{|c|c|c|c|c|c|c|c|c|}
\hline \multirow[b]{2}{*}{ Valve related events } & \multicolumn{2}{|c|}{ Events (n) } & \multicolumn{2}{|c|}{ LOR (per 100 patient-years) } & \multicolumn{2}{|c|}{ Outcome, death rate } & \multicolumn{2}{|c|}{ Reoperation rate } \\
\hline & Mech & Bio & Mech & Bio & Mech & Bio & Mech & Bio \\
\hline Valve thrombosis & 39 & 2 & 0.16 & 0.01 & 0.22 & 0.67 & 0.63 & 0.33 \\
\hline Thromboembolism & 419 & 717 & 1.6 & 1.3 & 0.17 & 0.18 & 0 & 0.01 \\
\hline Haemorrhage & 419 & 189 & $1.6^{*}$ & 0.4 & 0.14 & 0.2 & 0 & 0 \\
\hline Endocarditis & 89 & 240 & $3.9 / 0.66 \dagger$ & $3.2 / 0.48 \dagger$ & 0.43 & 0.36 & 0.53 & 0.5 \\
\hline NSD & 70 & 91 & 0.29 & 0.3 & 0.04 & 0 & 0.37 & 0.43 \\
\hline SVD & 0 & 469 & 0 & $\ddagger$ & 0 & 0.12 & 0 & 0.75 \\
\hline
\end{tabular}

*A Gompertz model was constructed.

†A two period exponential model was constructed for risk during and after the first six months after implantation.

$\ddagger$ A Weibull model was constructed incorporating age dependency.

Bio, bioprosthesis; LOR, linearised occurrence rate (or hazard); Mech, mechanical valve; NSD, non-structural dysfunction; SVD, structural valvar deterioration.

\section{DISCUSSION}

Simulation methods are widely used in operations research and management science. ${ }^{32}$ A well known example of a simulation program is the flight simulator in the aviation industry. Although not commonly used in clinical medicine, simulation models have been used previously to determine the prognosis of patients after aortic valve replacement..$^{33}$ We have designed a microsimulation model which calculates the outcomes of patients after aortic valve replacement. Compared with standard statistical techniques, the added value of microsimulation is that it allows modelling of the complex outcome pathways resulting from the many simultaneous risks, and provides detailed insight into the outcomes of patients following valve replacement, deducible to the individual patient. The structure of the model incorporates a schematic representation of the lives of patients with aortic valve replacement (fig 1) and, in principle, the model can be applied to any valve type. For this analysis, data from meta-analysis of published reports were incorporated into the model to predict the outcomes of patients after aortic valve replacement with bileaflet mechanical valves and stented porcine bioprostheses, respectively.

Ideally for simulation methodology, a comprehensive dataset should be available. This dataset should contain detailed information on a wide range of patients, including data on all valve related events and long term follow up. However, such a database is hard to assimilate and is not available at present. Hence we pooled empirical data and quantified estimates required to parameterise the model. An advantage of pooling data was that it represented the

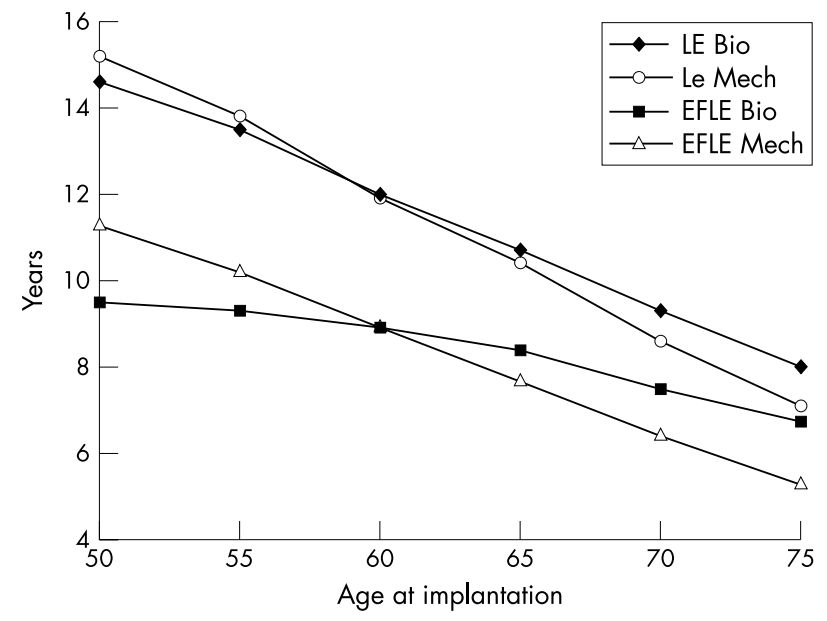

Figure 2 Comparison of life expectancy and event-free life expectancy in men after aortic valve replacement with mechanical valves and bioprostheses. experience of many institutions and countries and thereby enhanced the generalisability of the results. We selected the St Jude Medical valve, a bileaflet low profile prosthesis, to represent the mechanical valves. It is one of the most commonly implanted mechanical prostheses at present. ${ }^{1}$ We further selected five types of stented porcine bioprosthesis, both first and second generation, to represent the bioprostheses. No overt differences in the performance of these valves have been documented in published reports. ${ }^{35-38}$
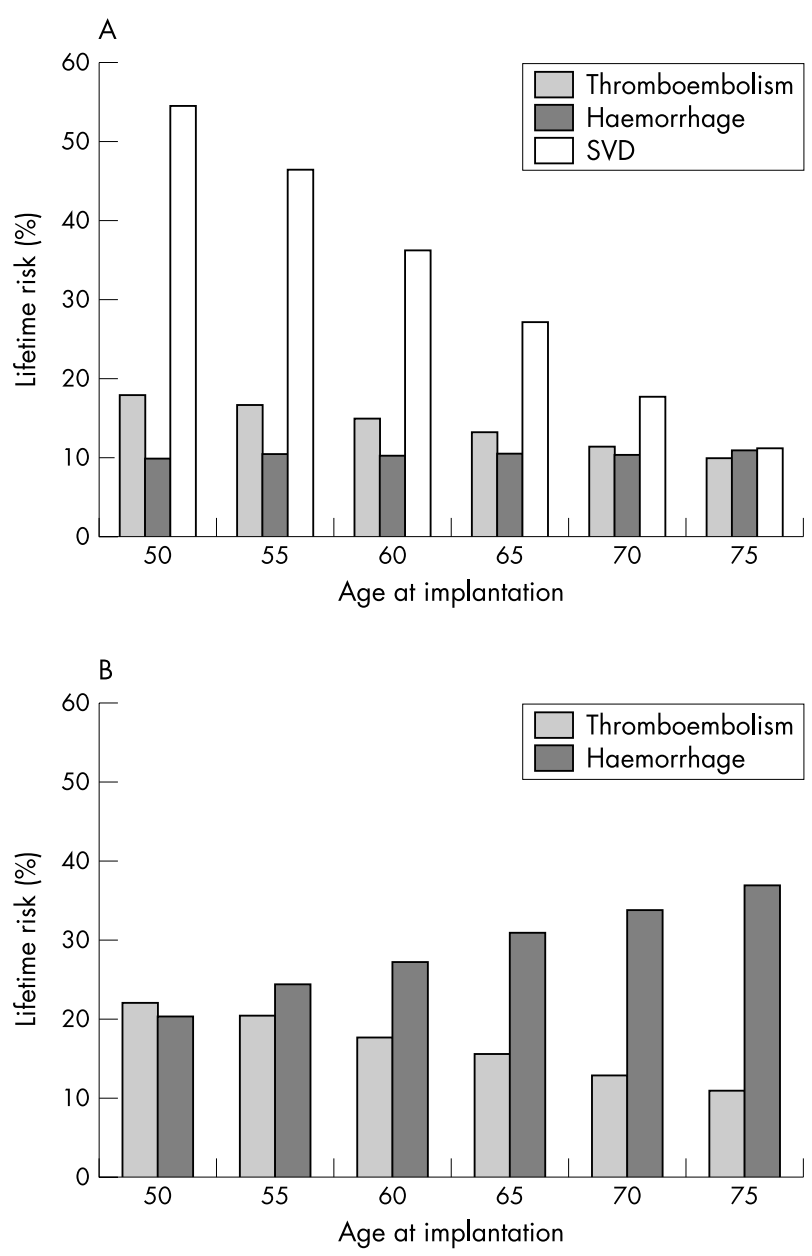

Figure 3 (A) Lifetime risk of thromboembolism, haemorrhage, and structural valvar deterioration following aortic valve replacement with bioprostheses in men of different ages. (B) Lifetime risk of thromboembolism and haemorrhage following aortic valve replacement with mechanical valves in men of different ages. 

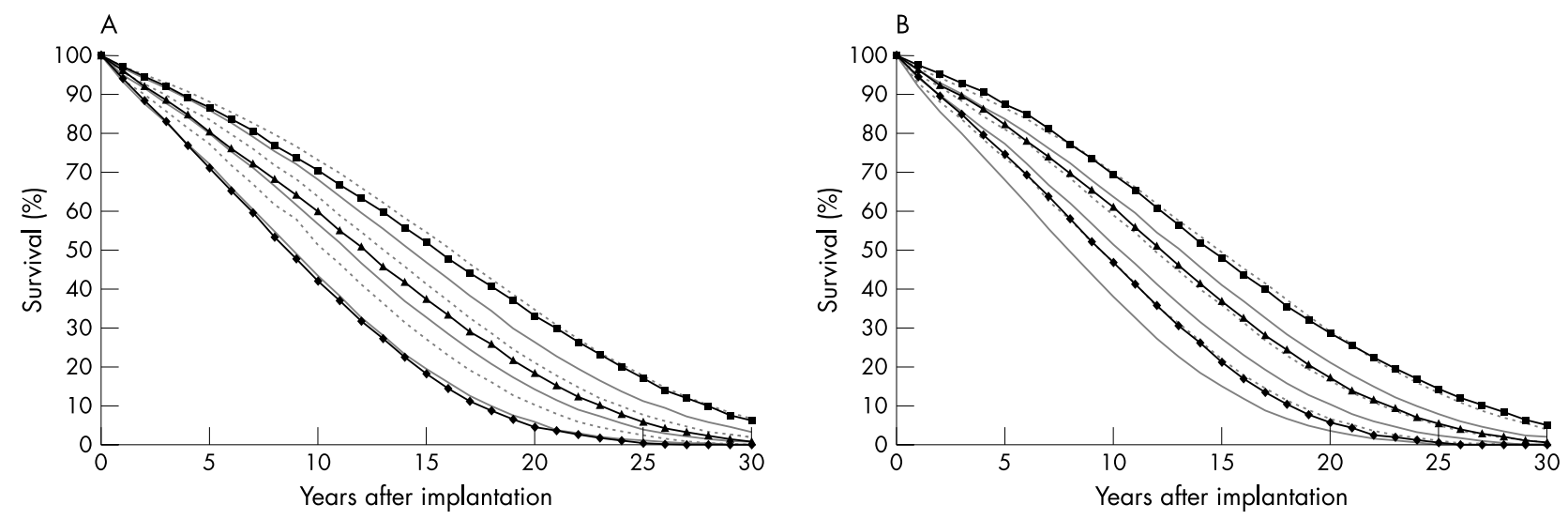

\begin{tabular}{|c|c|c|}
\hline $\begin{array}{l}\longrightarrow \mathrm{Mo} \\
\longrightarrow \mathrm{Mo} \\
\longrightarrow \mathrm{Mo}\end{array}$ & $\begin{array}{l}\text { Portland: } C A B C \\
\ldots \ldots \text { Portland: } C A B C \\
\ldots \ldots \text { Portland: } C A B C\end{array}$ & $\begin{array}{l}\text { Portland: CABG }(+) \\
\text { Portland: CABG }(+) \\
\text { Portland: CABG }(+)\end{array}$ \\
\hline
\end{tabular}

Figure 4 (A) Comparison of microsimulation model output and corresponding Portland data for 50, 60, and 70 year old men after aortic valve replacement with mechanical valves. (B) Comparison of microsimulation model output and corresponding Portland data for 50, 60, and 70 year old men after aortic valve replacement with bioprostheses.

The actuarial method and the Kaplan-Meier analysis have been used in many studies to estimate the survival of patients after aortic valve replacement. However, when applied to non-fatal complications such as SVD, the risk described is what patients would experience provided they were immortal, and answers the hypothetical question "what is the risk of the event if no patient ever died?". A more relevant estimate is the actual percentage of patients who will experience an event before they die. Estimation of the cumulative incidence-termed "actual" analysis in the cardiac literature-has recently gained interest. ${ }^{39}$ This method modifies the survival estimate to exclude future events attributed to already dead patients, and answers the question "what is the lifetime risk of the event?". The microsimulation model provides estimates of the lifetime risk of valve related events (fig 3, panels A and B). Thus, for example, a 65 year old man would have a $48 \%$ risk of experiencing at least one valve related event if he had a mechanical valve replacement, compared with $44 \%$ if he had a bioprosthesis. The age crossover point was 63 years. As depicted in fig 3, panels A and B, the crossover point in overall valve complications follows the increasing risk of haemorrhage with advancing age of implantation in mechanical valves, balanced against the decreasing risk of SVD with advancing age in bioprostheses.

The model predicted a life expectancy of 10.4 and 10.8 years, respectively, for a 65 year old man following implantation with a mechanical valve and a stented bioprosthesis. Considering life expectancy, the age crossover point between either valve type was 59 years. This result concurs well with the results of Birkmeyer and colleagues, ${ }^{33}$ who used a Markov state transition model to simulate the prognosis of patients with aortic valve replacement. They obtained a crossover point of 60 years. The microsimulation model also calculates the EFLE after aortic valve replacement. For the 65 year old male patient, for example, the model predicted an EFLE of 7.7 and 8.4 years, respectively, for mechanical valves and bioprostheses. Considering EFLE, the age crossover point between either valve type was 60 years.

Results from previous randomised studies ${ }^{40}{ }^{41}$ and another long term prospective study ${ }^{4}$ indicate that there is no significant difference in outcome after implantation with mechanical valves and bioprostheses. The American College of Cardiology and the American Heart Association guidelines ${ }^{3}$ recommend a bioprosthesis for patients $\geqslant 65$ years of age who do not have risk factors for thromboembolism, based on the reduced risk of SVD and the increasing risk of haemorrhage above this age. Our results suggest that, contrary to current recommendation, a bioprosthesis can be considered for patients under 65 years of age. New strategies being developed to retard mineralisation of xenograft valves ${ }^{2}$ - with, one hopes, a concomitant reduction in SVD risk-would further support reduction of the 65 year old threshold. Nevertheless, patient related factors including

Table 4 Summary of one way sensitivity analysis

\begin{tabular}{|c|c|c|c|c|c|c|c|}
\hline \multirow[b]{2}{*}{ Variable (valve type) } & \multirow{2}{*}{$\begin{array}{l}\text { Baseline } \\
\text { estimate }\end{array}$} & \multicolumn{2}{|c|}{ Plausible range* } & \multicolumn{2}{|c|}{ Event-free life expectancy (years) $\dagger$} & \multicolumn{2}{|c|}{ Age crossover pointł } \\
\hline & & Favourable & Unfavourable & Favourable & Unfavourable & Favourable & Unfavourable \\
\hline Thromboembolism (mech) & 1.6 & 1.2 & 2 & 9.1 & 8.6 & 62 & 58 \\
\hline Thromboembolism (bio) & 1.3 & 1 & 1.6 & 9.1 & 8.7 & 59 & 61 \\
\hline Haemorrhage (mech)§ & 1.3 & 1 & 1.7 & 9.2 & 8.5 & 62 & 58 \\
\hline Endocarditis (mech) & 0.7 & 0.5 & 0.9 & 9 & 8.7 & 61 & 59 \\
\hline SVD (bio) & 16 years & 17.6 years & 14.4 years & 9.2 & 8.5 & 57 & 63 \\
\hline
\end{tabular}

*The plausible range was defined by increasing or decreasing the baseline estimates for thromboembolism, haemorrhage, and endocarditis by $25 \%$. For SVD, the median time to SVD was varied by $10 \%$.

TThe event-free life expectancy (EFLE) calculated by the model was 8.9 years for a 60 year old man with baseline estimates.

¥The age crossover point between mechanical valves and bioprostheses was 60 years for EFLE at baseline analysis.

$\S$ Data from another study ${ }^{5}$ were used to model haemorrhage in mechanical valves. The baseline risk was varied for this analysis.

bio, bioprosthesis; mech, mechanical valve; SVD, structural valvar deterioration. 
individual hazards for valve related events (for example, increased risk of bleeding), patient preference, type of surgery, and health care delivery factors also need to be considered in the decision making process for valve choice in the individual patient. ${ }^{42}$ The long term results for mechanical valves and bioprostheses, calculated using our model, agreed with the corresponding long term follow up data from Portland, Oergon ${ }^{30}$ (fig 4, panels A and B). However, for most age groups, the British patients ${ }^{31}$ appeared to have a somewhat better survival than the model results and the American patients. The smaller number of patients in the UK data during the latter part of follow up might account for this discrepancy. If systematically different criteria (New York Heart Association (NYHA) class, timing of surgery, and so on) were used in the selection of patients in the UK as compared with the USA, the "additional mortality" (see appendix) of the British patients could differ from their counterparts in the USA. The "additional mortality" inherent in patients with aortic valve replacement is incorporated into the model by means of age specific hazard ratios, and hence different hazard ratios may be required to model the UK patients.

Limitations of the model included certain structural adjustments made with respect to the valve related events. For example, valve thrombosis, thromboembolism, and nonstructural dysfunction was assumed to carry constant hazards. The risk of endocarditis was assumed to be constant during the early and late phases. These hazards may in fact be time and age dependent, and hence further knowledge is necessary to address these assumptions. Survival after aortic valve replacement has also been shown to depend on preoperative cardiac rhythm, the type of valve lesion, concomitant CABG, and NYHA functional status. ${ }^{43}$ Although the model incorporates these factors non-specifically by means of hazard ratios, it cannot determine the individual influence of these factors on overall survival. At present, the model can only predict outcome for an average risk profile. However, we are currently incorporating CABG into the model. Ultimately, we envisage the introduction of a user friendly microsimulation model on the internet, which could be used as a bedside tool by the cardiologist or surgeon. This microsimulation methodology could also find application in other fields of medicine.

\section{Conclusions}

We have described the use of microsimulation to provide insight into age and sex specific long term outcomes after aortic valve replacement. We suggest that the currently recommended age threshold for implanting a bioprosthesis could be lowered further.

\section{Authors' affiliations \\ J P A Puvimanasinghe, J J M Takkenberg, L A van Herwerden, A J J C Bogers, Department of Cardiothoracic Surgery, Erasmus MC, Rotterdam, Netherlands \\ M J C Eijkemans, E W Steyerberg, J D F Habbema, Centre for Clinical Decision Sciences, Department of Public Health, Erasmus MC, Rotterdam M B Edwards, K M Taylor, Department of Cardiothoracic Surgery, Imperial College School of Medicine, London, UK \\ G L Grunkemeier, Providence Health System, Portland, Oregon, USA}

\section{APPENDIX \\ Input microsimulation model}

\section{VALVE RELATED EVENTS}

The annual hazards of valve thrombosis, thromboembolism, and non-structural dysfunction (NSD) were considered to be constant over time. Weighted pooling was used to obtain combined estimates of the linearised annual occurrence rates
(LOR) for these events. The estimates for endocarditis, and for SVD in bioprostheses, were obtained by pooling the respective freedom-from-event curves. ${ }^{44}$ The risk of endocarditis was assumed to take two phases of constant hazard, with the hazard during the first six months greater than the subsequent period. Therefore, we fitted two-period exponential models to the pooled freedom-from-endocarditis curves of the two valve types.

The risk of SVD in bioprostheses depends on the time elapsed since valve replacement and the age of the patient at implantation. This relation is well described by a Weibull model. ${ }^{45}$ The Weibull model is a generalisation of the exponential distribution, which incorporates an additional shape parameter. The shape parameter reflects the changing risk of SVD over time. We estimated the shape parameter from the pooled freedom from SVD curve and calculated the age effect from another selected study. ${ }^{20}$ The formula for freedom from SVD is:

$$
\mathrm{S}(\mathrm{t})=\mathrm{e}^{-(\mathrm{t} / \sigma) \wedge \beta}
$$

where $S(t)$ indicates the probability of remaining free from SVD at time t, while $\sigma$ and $\beta$ denote the scale and shape parameters of the model. The value of $\sigma$ depends on age:

$$
\sigma=\mathrm{e}^{2.21+0.0112 *} \text { age } \text { while } \beta=3.35 .
$$

With these parameters, the median time to SVD was 15.1, 16.8 , and 18.8 years, respectively, for 55,65 , and 75 year old male patients. As per meta-analysis, a zero risk of SVD was assigned for the mechanical valves.

Incorporating data from a previous study, ${ }^{5}$ haemorrhage after aortic valve replacement with mechanical valves was modelled using the Gompertz distribution, which takes into account the exponentially increasing hazard of that event with patient age. Mortality and reoperation rates associated with individual valve related events was also estimated (table 3).

\section{OPERATIVE MORTALITY}

Operative mortality was estimated at $1.5 \%$ for a 40 year old male patient, increasing with odds ratios of 1.022 per year and 1.7 with every reoperation.

\section{REFERENCES}

1 Bloomfield P. Choice of heart valve prosthesis. Heart 2002;87:583-9.

2 Edmunds LH. Evolution of prosthetic heart valves. Am Heart $J$ 2001;141:849-55.

$3 \mathrm{ACC} / \mathrm{AHA}$ guidelines for the management of patients with valvular heart disease. A report of the American College of Cardiology/American Heart Association. Task force on practice guidelines (committee on management of patients with valvular heart disease). J Am Coll Cardiol 1998;32:1486-588.

4 Khan SS, Trento A, DeRobertis M, et al. Twenty-year comparison of tissue and mechanical valve replacement. J Thorac Cardiovasc Surg 2001;122:257-69.

5 van der Meer FJ, Rosendaal FR, Vandenbroucke JP, et al. Assessment of a bleeding risk index in two cohorts of patients treated with oral anticoagulants. Thromb Haemost 1996;76:12-16.

6 Edmunds $\mathrm{LH}$, Cohn LH, Weisel RD. Guidelines for reporting morbidity and mortality after cardiac valvular operations. J Thorac Cardiovasc Surg 1988;96:351-3.

7 Edmunds LH, Clark RE, Cohn LH, et al. Guidelines for reporting morbidity and mortality after cardiac valvular operations. The American Association for Thoracic Surgery, Ad Hoc Liaison committee for standardizing definitions of prosthetic heart valve morbidity. Ann Thorac Surg 1996;62:932-5.

8 Peterseim DS, Cen YY, Cheruvu S, et al. Long-term outcome after biologic versus mechanical aortic valve replacement in 841 patients. J Thorac Cardiovasc Surg 1999;117:890-7.

9 Smith JA, Westlake GW, Mullerworth MH, et al. Excellent long-term results of cardiac valve replacement with the St Jude Medical valve prosthesis. Circulation 1993;88:I149-54.

10 Lund O, Nielsen SL, Arildsen H, et al. Standard aortic St Jude valve at 18 years: performance profile and determinants of outcome. Ann Thorac Surg 2000;69:1459-65.

11 Zellner JL, Kratz JM, Crumbley AJ, et al. Long-term experience with the St Jude Medical valve prosthesis. Ann Thorac Surg 1999;68:1210-18. 
12 Horstkotte D, Schulte H, Bircks W, et al. Unexpected findings concerning thromboembolic complications and anticoagulation after complete 10 year follow up of patients with St Jude Medical prostheses. J Heart Valve Dis 1993:2:291-301.

13 Aoyagi S Oryoii A, Nishi Y, et al. Long-term results of valve replacement with the St Jude Medical valve. J Thorac Cardiovasc Surg 1994;108:1021-9.

14 Baudet EM, Puel V, McBride JT, et al. Long-term results of valve replacement with the St Jude Medical prosthesis. J Thorac Cardiovasc Surg 1995; 109:858-70.

15 Ibrahim M, O'Kane H, Cleland J, et al. The St Jude Medical prosthesis. A thirteen-year experience. J Thorac Cardiovasc Surg 1994;108:221-30.

16 Cohn LH, Collins JJ, Rizzo RJ, et al. Twenty-year follow-up of the Hancock modified orifice porcine aortic valve. Ann Thorac Surg 1998;66:S30-4.

17 Wilson ES, Jamieson MP. Carpentier-Edwards supra-annular bioprosthesis in the aortic position. Has altered design affected performance? J Heart Valve Dis 1996;5:40-4

18 Logeais Y, Langanay T, Leguerrier A, et al. Aortic Carpentier-Edwards supraannular porcine bioprosthesis: a 12-year experience. Ann Thorac Surg 1999:68:421-5.

19 Hurle A, Meseguer J, Llamas P, et al. Clinical experience with the CarpentierEdwards supra-annular porcine bioprosthesis implanted in the aortic position. $J$ Heart Valve Dis 1998;7:331-5.

20 Fann JI, Miller DC, Moore KA, et al. Twenty-year clinical experience with porcine bioprostheses. Ann Thorac Surg 1996;62:1301-11; discussion 1311-12.

21 David TE, Ivanov J, Armstrong S, et al. Late results of heart valve replacement with the Hancock II bioprosthesis. J Thorac Cardiovasc Surg $2001 ; 121: 268-78$.

22 Bernal JM, Rabasa JM, Lopez R, et al. Durability of the Carpentier-Edwards porcine bioprosthesis: role of age and valve position. Ann Thorac Surg 1995;60:S248-52.

23 Westaby S, Horton $M$, Jin $X Y$, et al. Survival advantage of stentless aortic bioprostheses. Ann Thorac Surg 2000;70:785-90; discussion 790-1.

24 Jamieson WR, Munro Al, Miyagishima RT, et al. Carpentier-Edwards standard porcine bioprosthesis: clinical performance to seventeen years. Ann Thorac Surg 1995;60:999-1006; discussion 1007.

25 Jamieson WR, Janusz MT, Burr LH, et al. Carpentier-Edwards supraannular porcine bioprosthesis: second- generation prosthesis in aortic valve replacement. Ann Thorac Surg 2001;71:S224-7.

26 Orszulak TA, Schaff HV, Mullany CJ, et al. Risk of thromboembolism with the aortic Carpentier-Edwards bioprosthesis. Ann Thorac Surg 1995;59:462-8.

27 Akins CW, Carroll DL, Buckley MJ, et al. Late results with Carpentier-Edwards porcine bioprosthesis. Circulation 1990;82:IV65-74.

28 Sand ME, Naftel DC, Blackstone EH, et al. A comparison of repair and replacement for mitral valve incompetence. J Thorac Cardiovasc Surg 1987;94:208-19.
29 Takkenberg JJ, Puvimanasinghe JP, Grunkemeier GL. Simulation models to predict outcome after aortic valve replacement. Ann Thorac Surg 2003;75:1372-6

30 Grunkemeier GL, Chandler JG, Miller DC, et al. Utilization of manufacturers' implant card data to estimate heart valve failure. J Heart Valve Dis 1993;2:493-503.

31 Anon. The United Kingdom Heart Valve Registry Report (2000). London: UK Heart Valve Registry, 2002.

32 Law AM, Kelton WD. Simulation modeling and analysis. In: Riggs JL, ed. McGraw-Hill series in industrial engineering and management science. New York: McGraw-Hill, 1991.

33 Birkmeyer NJO, Birkmeyer JD, Tosteson ANA, et al. Prosthetic valve type for patients undergoing aortic valve replacement: a decision analysis. Ann Thorac Surg 2000;70:1946-52

34 Puvimanasinghe JP, Steyerberg EW, Takkenberg JJ, et al. Prognosis after aortic valve replacement with a bioprosthesis: predictions based on metaanalysis and microsimulation. Circulation 2001;103:1535-41.

35 Sarris GE, Robbins RC, Miller DC, et al. Randomized, prospective assessment of bioprosthetic valve durability. Hancock versus Carpentier-Edwards valves. Circulation 1993;88: II55-64.

36 Yun KL, Miller DC, Moore KA, et al. Durability of the Hancock MO bioprosthesis compared with standard aortic valve bioprostheses. Ann Thorac Surg 1995;60:S221-8.

37 Jamieson WR, Burr LH, Tyers GF, et al. Carpentier-Edwards standard and supra-annular porcine bioprostheses: 10 year comparison of structural valve deterioration. J Heart Valve Dis 1994;3:59-65.

38 Legarra JJ, Llorens R, Catalan M, et al. Eighteen-year follow up after Hancock II bioprosthesis insertion. J Heart Valve Dis 1999;8:16-24.

39 Grunkemeier GL, Wu Y. Interpretation of nonfatal events after cardiac surgery: actual versus actuarial reporting. J Thorac Cardiovasc Surg $2001 ; 122: 216-19$

40 Hammermeister K, Sethi GK, Henderson WG, et al. Outcomes 15 years after valve replacement with a mechanical versus a bioprosthetic valve: final report of the Veterans Affairs randomized trial. J Am Coll Cardiol 2000;36:1 152-8.

41 Bloomfield P, Wheatley DJ, Prescott RJ, et al. Twelve-year comparison of a Bjork-Shiley mechanical heart valve with porcine bioprostheses. N Engl J Med 1991;324:573-9.

42 Rahimtoola SH. Perspective on valvular heart disease: an update. J Am Coll Cardiol 1989;14:1-23.

43 Kvidal P, Bergstrom R, Horte LG, et al. Observed and relative survival after aortic valve replacement. J Am Coll Cardiol 2000;35:747-56.

44 Earle CC, Pham B, Wells GA. An assessment of methods to combine published survival curves. Med Decis Making 2000;20:104-11.

45 Grunkemeier GL, Bodnar E. Comparative assessment of bioprosthesis durability in the aortic position. J Heart Valve Dis 1995;4:49-55.

\section{ELECTRONIC PAGES}

\section{Heart Online case reports: www.heartjnl.com}

$\mathrm{T}$ he follow electronic only articles are published in conjunction with this issue of Heart.

\section{Fatal fulminant myocarditis caused by disseminated mucormycosis}

A Basti, S Taylor, M Tschopp, J Sztajzel

Acute fulminant myocarditis is a critical clinical condition with sudden onset of severe congestive heart failure followed by severe haemodynamic deterioration. Instituting early left ventricular support may improve outcome and result in better long term survival. The case of an immunocompromised patient who developed acute fulminant myocarditis in the setting of disseminated mucormycosis is presented.

(Heart 2004;90:e60) www.heartjnl.com/cgi/content/full/90/ $10 / \mathrm{e} 60$

\section{Intravascular ultrasound findings of coronary wall morphology in a patient with pseudoxanthoma elasticum \\ K Miwa, T Higashikata, $\mathrm{H}$ Mabuchi}

Pseudoxanthoma elasticum (PXE) is an inherited disorder characterised by progressive calcification of the elastic fibres in the skin, eye, and cardiovascular system. Recently, mutations in the ATP binding cassette transporter gene (ABCC6) were identified as cause of this disease. Although patients with PXE often have coronary artery disease, little is known about the process and the mechanism of coronary artery disease in PXE. In this report, intravascular ultrasound
(IVUS) imaging was performed in a female patient with PXE seven years after the onset of skin lesion to assess the coronary wall morphology in detail. IVUS showed a unique five layer appearance without acoustic shadowing along the vessel wall observed in the angiographically normal portion. These findings may reflect the earlier stage of coronary artery disease caused by PXE before calcification of the internal elastic laminae.

(Heart 2004;90:e61) www.heartjnl.com/cgi/content/full/90/ 10/e61

\section{Percutaneous device closure of a pseudoaneurysm of the left ventricular wall}

P Clift, S Thorne, J de Giovanni

The percutaneous device closure of a left ventricular pseudoaneurysm is described in a 60 year old man with a history of myocardial infarction complicated by ventricular tachycardia and left ventricular aneurysm treated by coronary artery bypass grafting and aneursymectomy with ventricular tachycardia ablation. He subsequently developed a vast pseudoaneurysm of the left ventricle with New York Heart Association functional class II heart failure symptoms. The selection of the approach and type of device used to close the neck of the pseudoaneurysm are discussed.

(Heart 2004;90:e62) www.heartjnl.com/cgi/content/full/90/ 10/e62 